\title{
How Popular North American Movie Represents Chinese
}

\author{
Adib Rifqi Setiawan \\ Alobatnis Research Society $(\Lambda \mathrm{RS})$ \\ Pandak, Colo, Kec. Dawe, Kabupaten Kudus, Jawa Tengah, 59353, Indonesia \\ rosenatorwarrior@gmail.com
}

\begin{abstract}
This article discusses common tropes and depictions of Chinese people and Chinese culture in popular North American Movie. Drawing on examples of homogenizing (East, South East) Asian identities, appropriation of Chinese cultural symbols or practices, Yellow-face as a common practice for playing Asian characters, and both the hyper-masculinization and emasculation of Chinese men, this paper argues that while there is a slow shift in Hollywood to address these issues, the context of anti-Chinese racism is prevalent in the mainstream movie industry.
\end{abstract}

Keywords: yellow-face, Chinese representation in movie, typecasting, miscasting, cultural appropriation

This narrative article will discuss the misrepresentation of Chinese people in North American popular culture and analyze examples in movie to look at the ways in which these misrepresentations can significantly impact one's existing schemas. Presently, the term "Asian" is often used as a blanket term that includes many subgroups in Asia. This could include people from Indonesia, Korea, Iran, India, and many more countries but, people in North America generally assume "Asian" refers to Chinese people. By assuming that the usage of "Asian" in North American popular culture refers to Chinese people, other groups in Asia are overlooked and misrepresented. Representation of Chinese people in popular culture can highlight the barriers and struggles they face in Western countries. For example, characteristics of femininity have been seen to misrepresent the concept of being a "woman" as it limits their options of expression. By restricting one's options, an individual's development is limited, and therefore oppressed. The same concept can be applied to what North American society considers "Asian", since an individual's options for expression are limited by the misrepresentations in popular culture, other expressions of being "Asian" are erased.

Chinese representation in North American popular culture has garnered increased attention through movies like Crazy Rich Asians (which focused on Singaporean and Chinese cultures), where East Asian people have seen a rise of more accurate representations in popular movie. However, this article aims to explore depictions of Chinese people that have been normalized in Western popular culture: (1) the blurring of distinct Asian identities into one homogenous and easily replaceable Other; (2) the appropriation of Chinese stories retold through the narrative lens of Western media; (3) the portrayal of Chinese men as either hyper-masculine or through an emasculated lens to fit the perception of an undesirable Other; (4) casting white actors to play Asian characters. 
Popular opinion is heavily influenced by cultural representations in the media that depict people's race or ethnicity inaccurately (Amin-Khan, 2012). We can understand these representations as constructing what psychologists call "schemas." Schemas are our mental representations that give us frameworks that set our preconceptions to understand future experiences. These schemas can be altered by past experiences, beliefs, and knowledge. Schemas can bias our perceptions of reality and future experiences because we try to make them consistent with what we already know (Shiraev \& Levy, 2016). To create our schemas, the differences in other theories are highlighted and our mental representations accept ideas that align with our own to further our internal concept (Zhu, 2013).

How does misrepresentation affect Chinese people in North America and their own selfperception of their culture and identity? While Chinese culture is prevalent in many media contexts, there seems to be a confusion when it comes to differentiating different "Asian" cultures in the media. A common mistake is confusing Chinese culture with Japanese culture in pieces that are written by American authors. East Asian cultures seem to blend together and this shows a large misunderstanding that is constructed with these inaccurate representations. Such misrepresentations foster misunderstanding among the general public where the audience is exposed to inaccurate information that could contribute to their existing schema of what they think to be true of Chinese culture or any Asian culture (Chen, 2009).

In Crazy Rich Asians, actress Sonoya Mizuno plays a Chinese character, Araminta Lee. Sonoya is of half Japanese and half British descent which creates an inaccurate representation of the movie's character that is misleading to the audience. The normalized culture that a Japanese person can act as a Chinese person, vice versa, or casting a person from another Asian culture entirely further blurs the lines between distinct Asian identities and makes them easily replaceable Others.

The animated Disney movie, Mulan, is a great popular example of cultural appropriation that set precedent of how Chinese values were shown from its release in 1998. The movie inappropriately depicts traditional Chinese symbols for comedic effect. For example, one of the characters is a lizard-sized dragon named Mushu, whose name is the same as an ethnically Chinese dish. It would be equally illogical to have a cowboy named "Cornbread" in a Western movie. Ethnic aspects of the movie were altered to portray a Western "dominant" culture with feminist values. Many male characters in the movie were shown as cruel and suggested a heavily patriarchal society. To appeal to a Western audience, aspects of the 'Other' were highlighted to make Chinese culture more exotic and different than Western culture. The movie, which was adapted from the original Ballad of Mulan poem which focused on loyalty, feminism, and filial piety - a concept in which elders are respected and supported by their children or younger generations, is warped and distorted in Disney's adaptation. Mulan focused on individuality which is a widely Western concept, it highlights that the female characters are exotic rather than recognizing that they were strong females, and portrays Chinese society as backwards by emphasizing patriarchy in the altered male roles (Yin, 2014). Since this movie was marketed as a children's movie, it could have had a large impact in contributing to many schemas of Chinese people. By altering the story's focus to Mulan's individuality and drive to gain freedom from her family, it reinforces that Chinese families put constraints on their children and are a restrictive culture. These changes distort Chinese stories and they are culturally appropriated to fit the marketing needs of Western media by highlighting Western values. 
Chinese men in Hollywood movies are often portrayed as either hyper-masculine or through an emasculated lens to further the concept of Otherness. Bruce Lee is a well-known actor that became the icon of Chinese masculinity that would be attractive to white female protagonists. In other popular movies such as Sixteen Candles with Long Duk Dong's portrayal of an "Asian" student, he is at times portrayed in an emasculated manner or as aggressive to fit the perception of an undesirable 'Other'. The portrayal of Chinese people as someone to ridicule or as dangerous further builds the image of white men being superior in many ways. Other Chinese representations of 'cool' kung fu masters include Jackie Chan in the Rush Hour series and Jet Li in many other action movies in the late 1990s to the early 2000s. Although these male leads were characterized as being heroes, there are still many stereotypes and racist 'jokes' that are in the movies. In Rush Hour, Jackie Chan plays a police officer seen as a protagonist yet he is referred to as the "Chung King cop" because he is Chinese. This undermines the legitimacy of his character as a police officer and emasculates his abilities in comparison to other non-Chinese officers in the movie. The subtle 'jokes' that reinforce Chinese stereotypes throughout the movie enforce white supremacy. In a way, the portrayal of these Chinese men and their masculinity contradict each other since on one hand they are this cool, fighting hero but on the other hand, they are still reduced to 'jokes' with stereotypes (Zhu, 2013).

Hollywood movies have a history of casting actors that are not Asian to play "Asian" roles, described as Yellowface, by which white actors have makeup applied to mimic "Asian" features such as yellow skin and smaller eyes. A well-known historical example in movie is the Dr. Fu Manchu movie series that began in 1923 and ended in 1969 featuring white male actors in Yellowface to play Fu Manchu. Although examples of Yellowface being acceptable in media are fading, it still took nearly a century for this minor shift to occur (Masuchika, 2013). Ghost in the Shell was released in 2017 with Scarlett Johansson as the lead character in the movie's recreation of a Japanese anime. The major cast members in the anime are Japanese, yet the producers chose to cast Scarlett Johansson due to her popularity in North America and the fact that it would have presumably marketed well. There was controversy during the planning of the movie where people questioned why a white actress was cast for a Japanese role. In an attempt to fix the issue, Paramount and Dreamworks production had suggested that they could alter Scarlett's appearance using digital effects to look more Asian. This "solution" seems to be even more of a step backwards and the idea was ultimately scrapped. The movie was eventually released and contributed to the racist portrayal of Asian characters in media.

In 2016, Matt Damon was the male lead in The Great Wall where he played a European character instead of the movie having a lead Chinese actor and character. Other supporting male roles were played by well-known Chinese actors that could have played the male lead. But yet again, in order to appeal to the Western market, it seems a white male protagonist was still needed. Many felt this casting decision took away many opportunities for Chinese actors in the movie industry and did not allow for accurate representation. Disney's decision to have Liu Yifei, a Chinese-American actress, play Mulan in their live-action remake of Mulan can be interpreted as an attempt to correct the previous whitewashing of characters in popular culture that has become extremely controversial. The news that a Chinese actress was cast into a Chinese role led to plenty of positive feedback from viewers in 2017. However, this small victory sparks the question of why people should be relieved in the first place to see someone of the same race cast to play a character consistent with the actor's race. We should not need to celebrate accurate portrayals of race today. 
Along with the shift of an increase in accurate portrayals of race, Hollywood is hit with the movie Crazy Rich Asians in 2018 that changed the lens of "Asian" people in popular culture. This movie has a predominantly Chinese and South Asian cast and is celebrated by many as a large step forward in breaking stereotypes of Chinese people by having accurate representations of "Asian" people as most of the characters in the story are Chinese. Although the ingrained ideals of emasculated or hyper-masculine Chinese men still exist, women found "Asian" men to be less attractive than the average man. However, by casting a Malaysian-British as the lead male in a romantic role, the stereotypes of "Asian" men being undesirable and uninteresting could eventually be negated and seen as equally attractive compared to white males. The depictions of characters in movie is only a sliver of reality, if it carries any truth at all, but is often believed by those outside of the depicted cultural group especially if they do not have real life examples to counter those depictions. With increasingly accurate depictions of cultures in mainstream popular culture, individuals of the portrayed race could feel less pressured and stereotyped by the inaccurate depictions.

In light of casting actors of the correct race to play lead roles, Simu Liu received a lot of hate when he was cast to play Shang-Chi in Marvel's movie Shang-Chi and the Legend of the Ten Rings. Yet again, the effects of a history of emasculating and hyper-masculating Asian men are seen as many people deemed he was 'too ugly' to play the role of Marvel's first "Asian" superhero. These criticisms bring forth the connotations of attractiveness that our society has built. The measures of attractiveness that many of the criticisms are suggesting are influenced by Eurocentric and Western beauty standards. Simu Liu has publicly spoken against these criticisms and has expressed that he will not allow other's views to define who he is. This empowering drive that he has shown can help drive Chinese people in North America to disregard the misrepresentations in popular culture and create their own accurate narrative.

Our society is heavily influenced by our histories which often carry concepts that people don't necessarily agree with but they are hesitant to change their existing schemas. With the slow changes seen throughout the years, further activism to raise attention to the homogenization of Asian identities is needed for different groups to be recognized. Work still needs to be done to put a stop to cultural stereotyping, appropriation, and whitewashing in Western popular culture through further education to correct existing and future schemas. 


\section{Acknowledgement}

This article is dedicated to my role model Surotul Ilmiyah, of her amazing inspiring \& motivating not for her endless shaping my mindset. Surotul Ilmiyah will be defending her final examination for the Ph.D. degree on November 25, 2020 in Xiangya School of Public Health, Central South University (CSU). So amazing, proud, and lucky to be her mentee.

\section{References}

Amin-Khan, T. (2012, October 12). New Orientalism, Securitisation and the Western Media's Incendiary Racism. Third World Quarterly, 33(9), 1595-1610.

Chen, M. (2009, Spring). Seeking Accurate Cultural Representation: Mahjong, World War II, and Ethnic Chinese in Multicultural Youth Literature. Multicultural Education, 16(3), $2-10$.

Masuchika, G. N. (2013, January 18). "Yellowface" in movies: a survey of American academic collections. Collection Building, 32(1), 31-36.

Shiraev, E., \& Levy, D. (2016). Cross-Cultural Psychology: Critical Thinking and Contemporary Applications, Sixth Edition (6th ed.). Abingdon: Routledge.

Yin, J. (2014, November 10). Popular Culture and Public Imaginary: Disney Vs. Chinese Stories of Mulan. Javnost - The Public, 18(1), 53-74.

Zhu, Z. (2013, January 30). Romancing 'kung fu master'-from 'yellow peril'to 'yellow prowess'. Asian Journal of Communication, 23(4), 403-419. 